\title{
Article \\ Predictive Value of Estimated Lean Body Mass for Neurological Outcomes after Out-of-Hospital Cardiac Arrest ${ }^{\dagger}$
}

\author{
Sung Eun Lee ${ }^{1,2} \mathbb{D}$, Hyuk Hoon Kim ${ }^{1, * \mathbb{D}}$, Minjung Kathy Chae ${ }^{1} \mathbb{D}$, Eun Jung Park ${ }^{1} \mathbb{D}$ and Sangchun Choi $^{1}$ \\ 1 Department of Emergency Medicine, School of Medicine, Ajou University, 164 Worldcup-ro, Yeongtong-gu, \\ Suwon 16499, Korea; plumpboy@hanmail.net (S.E.L.); mutjeo@gmail.com (M.K.C.); \\ amita62@nate.com (E.J.P.); avenue5933@gmail.com (S.C.) \\ 2 Department of Neurology, School of Medicine, Ajou University, Suwon 16499, Korea \\ * Correspondence: hyukhoon82@gmail.com; Tel.: +82-31-219-7751; Fax: +82-31-219-7760 \\ + This work was performed in the Department of Emergency Medicine, School of Medicine, Ajou University.
}

Citation: Lee, S.E.; Kim, H.H.; Chae, M.K.; Park, E.J.; Choi, S. Predictive Value of Estimated Lean Body Mass for Neurological Outcomes after Out-of-Hospital Cardiac Arrest . J. Clin. Med. 2021, 10, 71. https:// doi.org/10.3390/jcm10010071

Received: 24 November 2020 Accepted: 24 December 2020 Published: 28 December 2020

Publisher's Note: MDPI stays neutral with regard to jurisdictional claims in published maps and institutional affiliations.

Copyright: (c) 2020 by the authors. Licensee MDPI, Basel, Switzerland. This article is an open access article distributed under the terms and conditions of the Creative Commons Attribution (CC BY) license (https: / / creativecommons.org/ licenses/by/4.0/).

\begin{abstract}
Background: Postcardiac arrest patients with a return of spontaneous circulation (ROSC) are critically ill, and high body mass index (BMI) is ascertained to be associated with good prognosis in patients with a critically ill condition. However, the exact mechanism has been unknown. To assess the effectiveness of skeletal muscles in reducing neuronal injury after the initial damage owing to cardiac arrest, we investigated the relationship between estimated lean body mass (LBM) and the prognosis of postcardiac arrest patients. Methods: This retrospective cohort study included adult patients with ROSC after out-of-hospital cardiac arrest from January 2015 to March 2020. The enrolled patients were allocated into good- and poor-outcome groups (cerebral performance category (CPC) scores 1-2 and 3-5, respectively). Estimated LBM was categorized into quartiles. Multivariate regression models were used to evaluate the association between LBM and a good CPC score. The area under the receiver operating characteristic curve (AUROC) was assessed. Results: In total, 155 patients were analyzed (CPC score $1-2$ vs. $3-5, n=70$ vs. $n=85$ ). Patients' age, first monitored rhythm, no-flow time, presumed cause of arrest, BMI, and LBM were different $(p<0.05)$. Fourth-quartile LBM ( $\geq 48.98 \mathrm{~kg}$ ) was associated with good neurological outcome of postcardiac arrest patients (odds ratio $=4.81,95 \%$ confidence interval $(\mathrm{CI}), 1.10-25.55, p=0.04$ ). Initial high LBM was also a predictor of good neurological outcomes (AUROC of multivariate regression model including LBM: 0.918). Conclusions: Initial LBM above $48.98 \mathrm{~kg}$ is a feasible prognostic factor for good neurological outcomes in postcardiac arrest patients.
\end{abstract}

Keywords: lean body mass; out-of-hospital cardiac arrest; prognosis; neurological outcome; neuroprotective effect

\section{Background}

Patients with return of spontaneous circulation (ROSC) after out-of-hospital cardiac arrest have low survival rates and poor neurological prognosis despite active treatments, such as intensive care unit (ICU) care and targeted temperature management (TTM) [1]. Critically ill patients with hypoxic-ischemic insults during cardiac arrest may be further injured by myocardial dysfunction, impaired cerebral autoregulation, and systemic inflammatory reaction after ROSC. Consequently, patients are at a risk of multiorgan damage, including the nervous system damage [2-4].

Although obesity, which is defined as a body mass index (BMI) $\geq 30 \mathrm{~kg} / \mathrm{m}^{2}$, is considered an important risk factor for cardio-cerebrovascular diseases, metabolic syndrome, overweight, and obese patients have better prognosis in critical conditions, thereby creating an "obesity paradox" [5-7]. Improved survival rates and better neurological outcomes were observed in postcardiac arrest patients with relatively higher BMI [8-10]. Although mechanisms underlying this "obesity paradox" have not been clearly elucidated, the pro- 
tective effect of obesity is based on large metabolic storage, less cachexia, and high muscle mass $[9,11]$.

High lean body mass (LBM), which is the weight of the entire body excluding fat components, reflects an individual's muscle mass better than BMI and predicts better clinical outcomes for cardiovascular and end-stage renal diseases patients [12-14]. However, research on the clinical implications of LBM in postcardiac arrest patients is scarce; hence, we investigated the prognostic impact of LBM on postcardiac arrest patients with the hypothesis that higher LBM is positively associated with better neurological outcomes in cardiac arrest survivors.

\section{Materials and Methods}

\subsection{Postcardiac Arrest Care and TTM}

At our institute, almost 90,000 patients visit the emergency department (ED) each year. Patients with ROSC after out-of-hospital cardiac arrest are assessed and examined in the ED. Patients indicated for TTM receive treatment based on the standardized protocol of our institution. The target temperature for our TTM protocol is $32-36{ }^{\circ} \mathrm{C}$. If a patient has hemodynamic instability, bleeding tendency, or severe infection, a higher target temperature of up to $36{ }^{\circ} \mathrm{C}$ could be applied by the treating physician. TTM is conducted with temperature-managing devices with a feedback loop system (Artic Sun ${ }^{\circledR}$ Energy Transfer Pads $^{\mathrm{TM}}$; Medivance Corp, Louisville, KY, USA, or Cool Guard Alsius Icy Heat Exchange Catheter; Alsius Corporation, Irvine, CA, USA). All patients receive sedative and analgesic treatments sufficiently. If necessary, their shivering and seizures are also controlled.

\subsection{Enrolled Patients and Study Design}

This retrospective cohort study included adult patients who underwent TTM after out-of-hospital cardiac arrest of nontraumatic origin and were admitted to the ICU for postcardiac arrest care from January 2015 to March 2020 in Ajou University Hospital, Republic of Korea. We excluded patients with end-stage cancer with a life expectancy of less than 6 months, and those who had a do-not-resuscitate order with consent from their families because they had not undergone TTM. In addition, we excluded pediatric patients younger than 18 years, patients who died within $72 \mathrm{~h}$ after undergoing TTM or who died owing to sustained multiple organ failure, patients with poor cerebral performance (cerebral performance category (CPC) score of 3 or 4) before cardiac arrest, patients with inadequate temperature management during TTM, and patients with missing or insufficient data. The finally enrolled patients were grouped on the basis of neurological outcomes according to CPC scores. We analyzed and compared the predictive values of BMI and LBM in postcardiac arrest patients.

\subsection{Data Collection}

Study data were retrospectively retrieved from electronic medical records and a data registry of postcardiac arrest patients who underwent TTM after ROSC. Demographic and clinical data, including age, sex, underlying disease (such as hypertension and diabetes), and cardiopulmonary resuscitation (CPR) information (such as whether the cardiac arrest was witnessed, whether bystanders performed CPR, time from collapse to administration of life support, time from the administration of life support until ROSC, first monitored rhythm, whether automated external defibrillator had been used, method of hypothermia, and patient outcomes (expressed as the CPC score)) were collected. Body weight was measured using built-in scales in our ICU beds (HL-SK-154, Hanlim, Cheongju, Korea) at admission. The built-in scales were adjusted to zero before each measurement. Height was also measured at admission as the ratio of the total length of the ICU bed to the height of the patient. We categorized BMI based on classification guidelines of the Korean Society for the Study of Obesity (underweight $=\mathrm{BMI}<18.5 \mathrm{~kg} / \mathrm{m}^{2}$; normal weight $=\mathrm{BMI}$ : $18.5-22.9 \mathrm{~kg} / \mathrm{m}^{2}$; overweight $=\mathrm{BMI} 23.0-24.9 \mathrm{~kg} / \mathrm{m}^{2}$; obese $=\mathrm{BMI} \geq 25 \mathrm{~kg} / \mathrm{m}^{2}$ ) [15].

LBM was calculated using the Kulkarni equation [16]. 
Men: $\operatorname{LBM}(\mathrm{kg})=-15.605-(0.032 \times$ age $(\mathrm{y}))+(0.192 \times$ height $(\mathrm{cm}))+(0.502 \times$ weight $(\mathrm{kg}))$.

Women: $\operatorname{LBM}(\mathrm{kg})=-15.034-(0.018 \times$ age $(\mathrm{y}))+(0.165 \times$ height $(\mathrm{cm}))+(0.409 \times$ weight $(\mathrm{kg}))$

We classified patients into quartiles according to their calculated LBMs (kilograms) (Level 1 = LBM < 32.71; Level 2 = LBM 32.72-44.17; Level 3 = LBM 44.18-48.97; Level $4=\mathrm{LBM} \geq 48.98$ ). As the primary outcome of this study, neurological outcome was assessed using the CPC score after 1 month or at discharge if the discharge was sooner than 1 month. A CPC score of 1 (good recovery) to 2 (moderate disability) was categorized as a good neurological outcome, and a CPC score of 3 (severe disability) to 5 (death or brain death) was considered a poor neurological outcome.

This study was conducted based on the principles of the Declaration of Helsinki and was approved by the institutional review board of Ajou University Medical Center (MED-MDB-20-283). The requirement for consent was waived because of the nature of this retrospective study.

\subsection{Statistical Analysis}

Continuous data are presented as mean \pm standard deviation or median with interquartile range, and categorical data are presented as numbers with percentages (\%). To assess intergroup differences, we used the Mann-Whitney U and Fisher's exact tests for continuous and categorical variables, respectively. Univariate analysis was performed to identify factors associated with neurological outcomes in postcardiac arrest patients. Univariate and multivariate logistic regression models were used to assess the association between primary outcome and LBM, with LBM considered the categorical variable. We included all possible confounders, such as sex, age, hypertension (yes/no), diabetes (yes/no), bystander basic life support (yes/no), no-flow time (time from collapse to administration of life support (minutes)), total CPR time (time from administration of life support until ROSC (minutes)), ventricular fibrillation or nonperfusion ventricular tachycardia as the first monitored rhythm (yes/no), use of an automatic external defibrillator (AED) during out-of-hospital resuscitation (yes/no), and methods of therapeutic hypothermia (gel pad/intravascular catheter), that could be associated with outcomes. We constructed receiver operating characteristic (ROC) curves to evaluate and compare the predictive values of multivariate models, which included BMI or LBM [17]. Statistical analyses were performed using $\mathrm{R}$ software for Mac version 3.2.2 (The R Project, Vienna, Austria). $p$-values $<0.05$ were considered statistically significant.

\section{Results}

\subsection{Baseline Characteristics of Patients}

Among 512 patients with ROSC after cardiac arrest who were treated in the ICU, 146 patients who did not undergo TTM were excluded. In total, 366 patients underwent TTM, but another 211 patients, including 132 patients who died within $72 \mathrm{~h}$ after undergoing TTM or who died owing to sustained multiple organ failure, and 79 patients who had incomplete data, were excluded. Finally, we enrolled 155 patients and categorized them into good$(n=70)$ and poor neurological outcome groups $(n=85)$ (Figure 1$)$. Baseline characteristics of all enrolled patients are shown in Table 1. Age was significantly different between the two outcome groups. Other general demographics, including sex and underlying disease, did not significantly differ between the two outcome groups. First monitored rhythm, no-flow time, advanced cardiopulmonary life support time, presumed cause of arrest, and the use of AED were statistically different between the two groups $(p<0.05)$. BMI and LBM, as continuous and categorical variables, respectively, were also significantly different between the two groups $(p<0.01$ and $p<0.01$, respectively; Table 1$)$. 
Table 1. Baseline characteristics of the study population.

\begin{tabular}{|c|c|c|c|}
\hline & Good CPC $(n=70)$ & Poor CPC $(n=85)$ & $p$-Value \\
\hline \multicolumn{4}{|l|}{ Patient characteristics } \\
\hline Age, (mean) years & $50.34( \pm 13.03)$ & $58.14( \pm 16.02)$ & $<0.01$ \\
\hline Female, $n(\%)$ & $14(20.00)$ & $29(34.12)$ & 0.08 \\
\hline Height, (mean) cm & $171.30( \pm 7.59)$ & $165.44( \pm 8.22)$ & $<0.01$ \\
\hline Weight, (mean) $\mathrm{kg}$ & $70.40( \pm 13.91)$ & $60.86( \pm 13.29)$ & $<0.01$ \\
\hline \multicolumn{4}{|l|}{$\begin{array}{l}\text { Known prearrest health } \\
\text { conditions }\end{array}$} \\
\hline Diabetes mellitus, $n(\%)$ & $16(22.86)$ & $26(30.59)$ & 0.37 \\
\hline Hypertension, $n(\%)$ & $25(35.71)$ & $40(47.06)$ & 0.06 \\
\hline \multicolumn{4}{|l|}{ Resuscitation factors } \\
\hline Witnessed cardiac arrest, $n(\%)$ & $60(85.71)$ & 65 (76.47) & 0.34 \\
\hline Bystander CPR, $n(\%)$ & $50(71.43)$ & $59(69.41)$ & 0.58 \\
\hline Initial shockable rhythm, $n(\%)$ & $55(78.57)$ & $10(11.76)$ & $<0.01$ \\
\hline No-flow time, min (IQR) & $2.74(0.00-4.00)$ & $6.14(0.00-10.00)$ & 0.02 \\
\hline Total CPR time, mean & $20.03( \pm 12.26)$ & $29.54( \pm 17.83)$ & $<0.01$ \\
\hline Out of hospital BLS time, min & $15.37( \pm 10.95)$ & $20.64( \pm 12.58)$ & 0.01 \\
\hline $\begin{array}{c}\text { ACLS time after hospital arrival, } \\
\min (\mathrm{IQR})\end{array}$ & $4.63(0-4.00)$ & 9.45 (4.00-12.00) & $<0.01$ \\
\hline Use of AED, $n(\%)$ & $59(84.29)$ & $23(27.06)$ & $<0.01$ \\
\hline \multicolumn{4}{|l|}{ TTM factors } \\
\hline TTM method, $n(\%)$ & & & 0.16 \\
\hline Gel pads with feedback loop & $62(87.27)$ & $69(81.18)$ & \\
\hline $\begin{array}{l}\text { Intravascular cooling with } \\
\text { feedback loop }\end{array}$ & $5(7.14)$ & $5(5.88)$ & \\
\hline Cooling water blanket & $3(4.29)$ & $11(12.94)$ & \\
\hline Target temperature, $n(\%)$ & & & 0.70 \\
\hline From 32 to $34{ }^{\circ} \mathrm{C}$ & $58(82.86)$ & $74(87.06)$ & \\
\hline From 35 to $37^{\circ} \mathrm{C}$ & $12(17.14)$ & $11(12.94)$ & \\
\hline \multicolumn{4}{|l|}{ Body-weight-related index } \\
\hline BMI, mean & $24.35( \pm 4.10)$ & $22.44( \pm 4.59)$ & $<0.01$ \\
\hline Underweight $(<18.50), n(\%)$ & $3(4.29)$ & $13(15.29)$ & \multirow{4}{*}{$<0.01$} \\
\hline Normal (18.50-22.99), $n(\%)$ & $25(35.71)$ & $40(47.06)$ & \\
\hline Overweight (23.00-24.99), $n(\%)$ & $13(18.57)$ & $18(21.18)$ & \\
\hline Obese $(\geq 25.00), n(\%)$ & $29(41.43)$ & $14(16.47)$ & \\
\hline LBM, mean & $48.90( \pm 9.21)$ & $42.64( \pm 10.74)$ & $<0.01$ \\
\hline Level $1(<32.71), n(\%)$ & $6(8.58)$ & $21(24.71)$ & \multirow{4}{*}{$<0.01$} \\
\hline Level 2 (32.72-44.17), $n(\%)$ & $12(17.14)$ & $23(27.06)$ & \\
\hline Level 3 (44.18-48.97), $n(\%)$ & $11(15.71)$ & $21(24.71)$ & \\
\hline Level $4(\geq 48.98), n(\%)$ & $41(58.57)$ & $20(23.53)$ & \\
\hline
\end{tabular}

$\mathrm{CPC}=$ cerebral performance category, $\mathrm{CPR}=$ cardiopulmonary resuscitation, BLS = basic life support, ACLS = advanced cardiovascular life support, AED = automatic external defibrillator, TTM = targeted temperature management, $\mathrm{BMI}=$ body mass index, $\mathrm{LBM}=$ lean body mass.

\subsection{Analysis of Factors Associated with Neurological Outcomes}

In the univariate analysis, high BMI and LBM were associated with good neurological outcomes after 1 month (obese BMI $\geq 25.00 \mathrm{~kg} / \mathrm{m}^{2}$ : odds ratio (OR), 3.31, 95\% CI, 1.50-7.62; $p=0.04$ and LBM Level 4: OR, 7.18; 95\% CI, 2.63-22.17; $p<0.01$ ). Furthermore, in the univariate analysis, other factors such as first monitored rhythm, no-flow time, low-flow time, presumed cause of cardiac arrest, and use of AED were associated with neurological outcomes after 1 month $(p<0.05)$. Even after adjusting for multiple confounding factors, including age, sex, history of diabetes, hypertension, presence of a witness, bystander CPR, first monitored rhythm, no-flow time, low-flow time, presumed cause of arrest, use of AED, and the methods of therapeutic hypothermia, LBM Level 4 was still associated with good neurological outcomes (OR, 4.81; 95\% CI, 1.10-25.55; $p=0.04$; Table 2). 
Table 2. Logistic regression models for clinical outcomes. Univariate odds ratios adjusted for multiple confounders.

\begin{tabular}{|c|c|c|c|c|c|c|}
\hline & $\begin{array}{c}\text { Univariate OR } \\
\text { (95\% CI) }\end{array}$ & $p$-Value & $\begin{array}{l}\text { Multivariate OR } \\
\text { (95\% CI), Model } \\
\text { Including BMI }^{\text {e }}\end{array}$ & $p$ Value & $\begin{array}{l}\text { Multivariate OR } \\
\text { (95\% CI), Model } \\
\text { Including LBM }\end{array}$ & $p$-Value \\
\hline Age & $0.96(0.94-0.98)$ & $<0.01$ & $0.96(0.93-0.99)$ & 0.02 & $0.96(0.92-0.99)$ & 0.03 \\
\hline $\begin{array}{l}\text { Initial shockable } \\
\text { rhythm }\end{array}$ & $\begin{array}{c}27.50 \\
(11.97-69.18)\end{array}$ & $<0.01$ & $18.32(5.04-79.17)$ & $<0.01$ & $17.38(4.64-70.27)$ & $<0.01$ \\
\hline No-flow time ${ }^{a}$ & $0.93(0.87-0.98)$ & 0.01 & $0.96(0.88-1.02)$ & 0.24 & $0.96(0.89-1.03)$ & 0.30 \\
\hline Total CPR time ${ }^{b}$ & $0.95(0.93-0.97)$ & $<0.01$ & $0.96(0.92-0.99)$ & 0.01 & $0.95(0.91-0.98)$ & 0.01 \\
\hline Use of AED & $13.53(6.25-31.51)$ & $<0.01$ & $1.39(0.33-5.27)$ & 0.63 & $1.59(0.38-6.03)$ & 0.51 \\
\hline $\begin{array}{l}\text { BMI (Cont.) } \\
\text { BMI }^{\mathrm{c}}\end{array}$ & $1.13(1.04-1.25)$ & $<0.01$ & $1.10(0.98-1.25)$ & 0.13 & & \\
\hline $\begin{array}{l}\text { Underweight } \\
\quad(<18.50)\end{array}$ & $0.37(0.07-1.28)$ & 0.15 & $0.40(0.04-3.39)$ & 0.44 & - & - \\
\hline $\begin{array}{c}\text { Normal } \\
(18.50-22.99)\end{array}$ & 1 & 1 & 1 & 1 & - & - \\
\hline $\begin{array}{l}\text { Overweight } \\
\text { (23.00-24.99) }\end{array}$ & $1.16(0.48-2.76)$ & 0.74 & $1.96(0.56-7.12)$ & 0.30 & - & - \\
\hline Obese $(\geq 25.00)$ & $3.31(1.50-7.62)$ & $<0.01$ & 3.27 (1.04-11.07) & 0.04 & - & - \\
\hline $\begin{array}{l}\text { LBM (Cont.) } \\
\text { LBM }^{\mathrm{d}}\end{array}$ & $1.07(1.03-1.11)$ & $<0.01$ & & & $1.05(0.99-1.10)$ & 0.09 \\
\hline Level $1(<32.71)$ & 1 & 1 & - & - & 1 & 1 \\
\hline $\begin{array}{c}\text { Level } 2 \\
(32.72-44.17)\end{array}$ & $1.82(0.60-6.06)$ & 0.30 & - & - & $1.31(0.25-7.37)$ & 0.75 \\
\hline $\begin{array}{c}\text { Level } 3 \\
(44.18-48.97)\end{array}$ & $1.83(0.59-6.18)$ & 0.31 & - & - & $9.85(0.18-5.52)$ & 0.98 \\
\hline Level $4(\geq 48.98)$ & $7.18(2.63-22.17)$ & $<0.01$ & - & - & 4.81 (1.10-25.55) & 0.04 \\
\hline
\end{tabular}

$\mathrm{CPR}=$ cardiopulmonary resuscitation, $\mathrm{AED}=$ automatic external defibrillator, $\mathrm{BMI}=$ body mass index, $\mathrm{LBM}=$ lean body mass, Cont. $=$ as continuous variable. ${ }^{a}$ No-flow time: time from collapse to administration of resuscitation ${ }^{b}$ Total CPR time: time from administration of resuscitation to return of spontaneous circulation (BLS time + ACLS time) ${ }^{c}$ Normal body mass index group as reference group. ${ }^{d}$ Lowest lean body mass group as reference group. ${ }^{\mathrm{e}}$ Hosmer-Lemeshow $\mathrm{X}$ squared $=6.95, \mathrm{df}=8, p$-value $=0.541$, indicating good model fit. Hosmer and Lemeshow test (binary model). ${ }^{\mathrm{f}}$ Hosmer-Lemeshow $\mathrm{X}$ squared $=9.77, \mathrm{df}=8, p$-value $=0.281$, indicating good model fit. Hosmer and Lemeshow test (binary model).

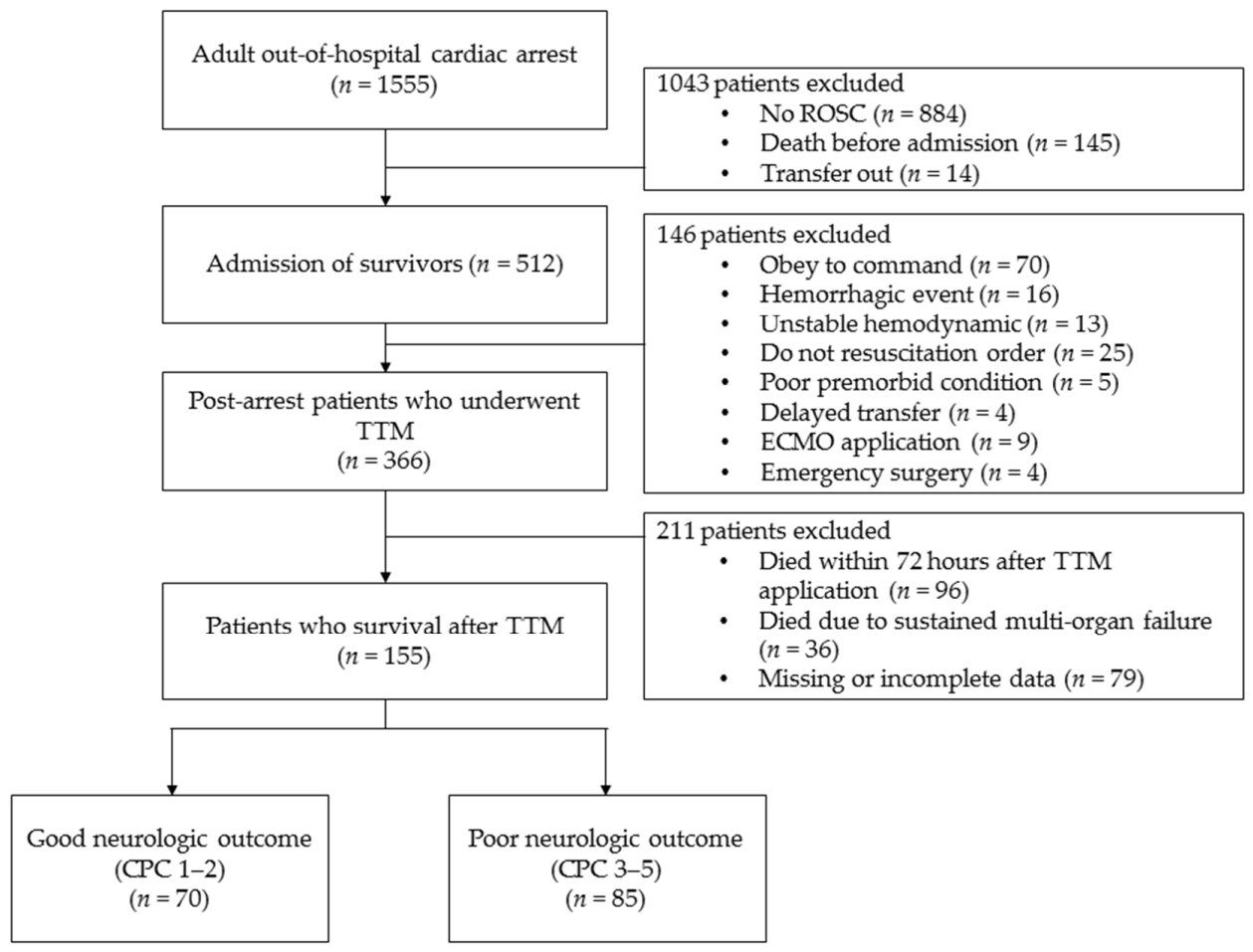

Figure 1. Study flowchart. 


\subsection{Prediction of Neurological Outcomes}

Initial high BMI and LBM Level 4 had good associations with good neurological outcomes. DeLong's test was performed for two areas under the ROC curve (AUROC) of multivariate models which include BMI or LBM. Both two multivariate models include variables representing significant odd ratios in univariate analysis, such as age, first monitored rhythm, total CPR time, no-flow time, and AED use. Additionally, BMI is included in Model 1 and LBM in model 2, respectively. And the two models were not significantly different (0.917 vs. 0.918, $p$ value $=0.77$; Figure 2$)$.

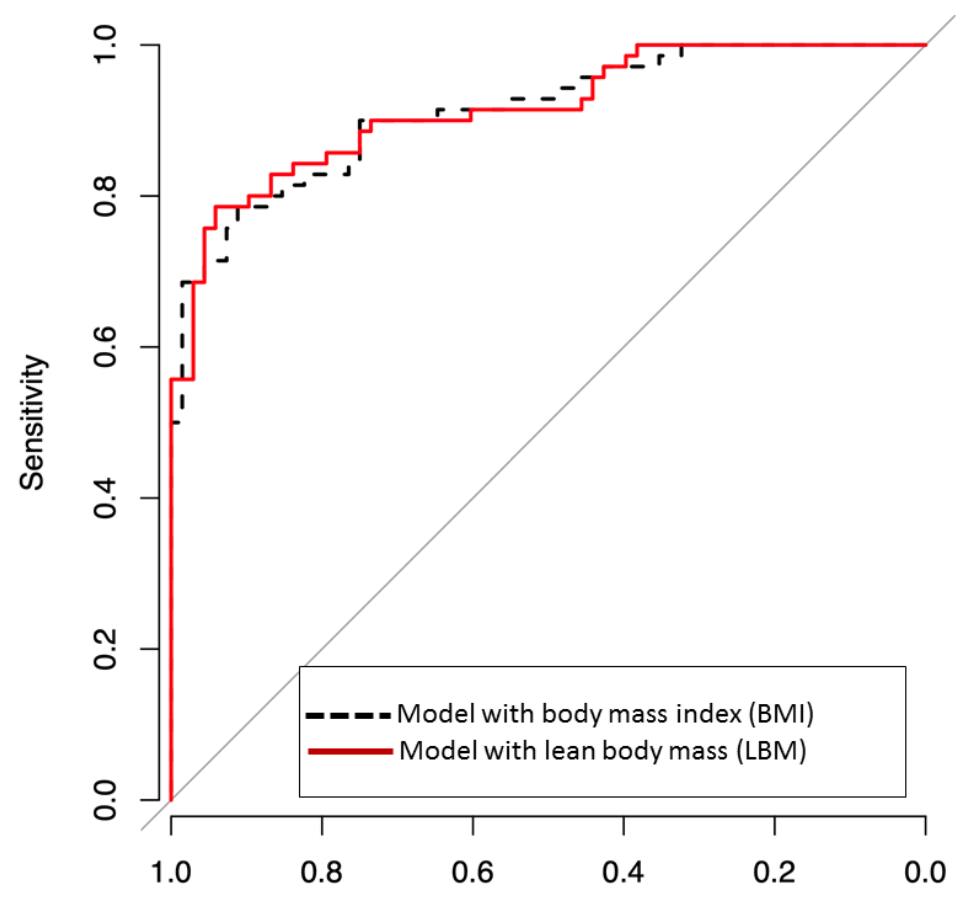

Figure 2. Receiver operating characteristic (ROC) curves for predicting good neurological outcome, defined as cerebral-performance categories 1-2, including body mass index (BMI) or lean body mass (LBM) in multivariate logistic models. Area under ROC curve (AUROC) was a good predictive value for BMI, and LBM predicted good neurological outcomes. The two models were not significantly different (AUROC of BMI vs. AUROC of LBM =0.917 vs. 0.918, $p$-value $=0.8715$ ).

\section{Discussion}

In this study, a high LBM of patients who had undergone TTM after cardiac arrest was significantly associated with a good neurological prognosis. These results are in line with those of a previous study that reported on the "obesity paradox" using BMI. Recent studies have reported that factors linked to obesity, such as cholesterol level, affect the prognosis of postcardiac arrest patients [18]. However, the mechanism underlying the obesity paradox is not clearly known. Our study demonstrated a relationship between LBM and neurological outcomes in postcardiac arrest patients.

Our result show that LBM and BMI models have similar predictive performance for predicting a good neurologic outcome (Figure 2). LBM is the weight of the entire body excluding fat components and reflects an individual's muscle mass better than BMI. In other words, patients with high LBM have large skeletal muscle mass, and this may have a favorable effect on postcardiac arrest via several mechanisms (Figure 3). Large muscle mass is associated with a good premorbid condition [19]. Skeletal muscle mass also plays an essential role in maintaining a metabolically healthy phenotype, especially in nonobese individuals. Besides the precardiac arrest condition, postcardiac arrest physiological reserve is better in patients with high LBM than in those with low LBM [20]. 


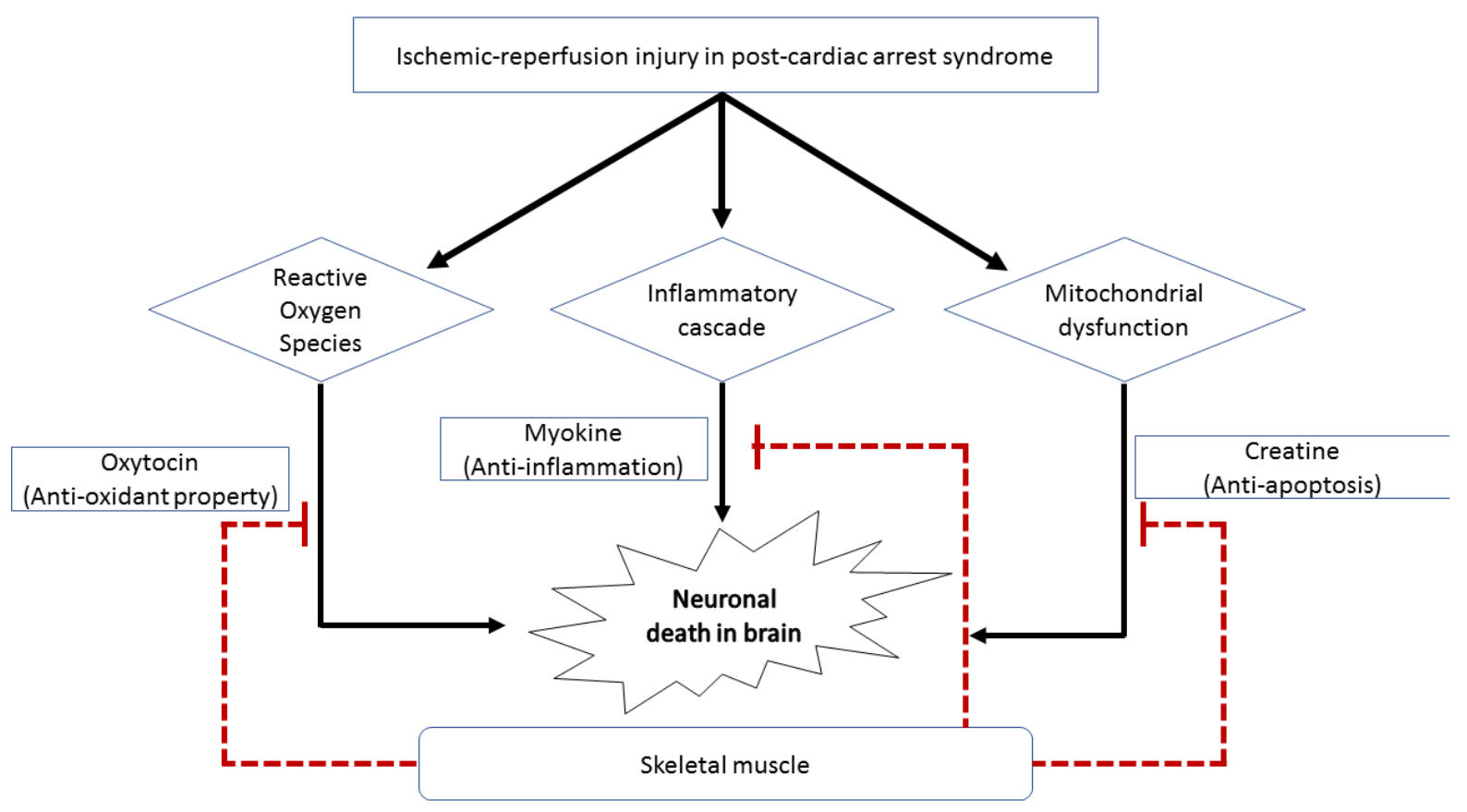

Figure 3. Schematic diagram showing the effects of skeletal muscle on the nervous system. Skeletal muscle can exhibit inhibitory effects on neuronal cell death in survivors after cardiac arrest via the (1) antioxidant property of oxytocin, (2) anti-inflammatory action of myokine, and (3) antiapoptotic activity of creatine.

Moreover, the in vivo and in vitro neuroprotective potential of the skeletal muscles has been reported as described below. First, a good neurological prognosis after cardiac arrest in patients with high LBM may be due to the large amount of creatine stored in the skeletal muscles. Creatine is one of several potential neuroprotectants against neurodegenerative diseases and ischemic diseases in the heart and brain [21,22]. Because LBM reflects muscle mass better than BMI does, LBM may also be a feasible prognostic factor. Second, a substantial amount of anti-inflammatory myokines excreted from abundant muscle mass may also play a protective role in patients with high LBM. Myokines are cytokines released by skeletal muscle. One of these myokines is interleukin-6 (IL-6), which has an extensive anti-inflammatory effect [23]. A previous study reported that IL-6 has a favorable prognostic effect on cerebral ischemia and dermatological diseases because it inhibits the production of tumor necrosis factor- $\alpha$ and IL-1, which are classical proinflammatory cytokines [24]. Neural damage in postcardiac arrest syndrome could be caused by unbalanced and aggressive inflammatory reactions after ischemia and reperfusion injuries. Therefore, this anti-inflammatory myokine, IL-6, may alleviate the risk of neurological injury arising from aggressive inflammatory insults after cardiac arrest. Third, oxytocin, which is mainly synthesized by the hypothalamic paraventricular and supraoptic nucleus, is expressed in myogenic cells and may have a protective role in patients with postcardiac arrest syndrome. In a recent experimental study, muscle tissue was considered a source of oxytocin [25]. Oxytocin has anti-inflammatory, antiapoptotic, and antioxidant properties that alleviate pathophysiological changes after ischemia-reperfusion in various human organs, including the bladder and heart. Oxytocin may also have a neuroprotective function in neurons against cerebral ischemia via the attenuation of calpain-1, which is implicated in the cell death process [26-28]. Therefore, the neuroprotective effect of LBM in patients with postcardiac arrest syndrome might be because of the increased expression of oxytocin. Moreover, skeletal muscles contribute to the stabilization of proteins (proteostasis) and metabolites in neurodegenerative disorders [29]. Cardiac arrest is a condition wherein the homeostasis of various organ functions, including maintenance of protein level, is affected. Thus, large skeletal muscle mass may help restore homeostasis and reduce further neuronal injury after the initial damage of cardiac arrest. 
This study had several limitations. First, we used a retrospective design and conducted the study at a single institution in Korea, with a limited number of patients. Thus, the results might not be generalizable to other ethnic groups. In the future, there may be a need for prospective studies involving larger and more diverse patient samples. Second, considering the baseline characteristics of the enrolled patients, there were significant differences in age, and, although not significant, there were differences in the proportion of sex between the two groups according to neurological outcomes. Confounders related to age and sex could have also influenced our results. Third, this study excluded patients who had died within $72 \mathrm{~h}$ after undergoing TTM or who died owing to sustained multiple organ failure, because we intended to check the neuroprotective effect of LBM by excluding patients who had died owing to systemic causes. However, this approach may have caused selection bias. Fourth, LBM could be estimated by more accurate modalities, including magnetic resonance imaging, computed tomography, and dual-energy X-ray absorptiometry [30,31]. Because this study was a retrospective one, we calculated the LBM using predictive equations based on data from medical records. The accuracy of the predictive equations may be low in ICU patients [32]. Furthermore, height, which is a key factor in calculating LBM, was estimated using the ratio of the ICU bed because the patient could not stand. Thus, height could have been less accurate than expected, with a possibility of interpersonal variability. Further studies wherein LBM is measured with accurate height values may be necessary. Finally, we used the Kulkarni equation, which was developed in India, among several other predictive equations. It is unclear whether the Kulkarni equation is the most suitable method for Koreans and Asians in general.

Despite these limitations, we believe that LBM could be a meaningful and feasible prognostic factor because it reflects muscle mass more accurately than BMI.

\section{Conclusions}

The study findings demonstrate that an LBM above $48.98 \mathrm{~kg}$ could be associated with a good neurological prognosis in patients who undergo TTM after cardiac arrest. Using LBM as an adjunctive prognostic factor, physicians could more precisely predict the neurological outcomes of postcardiac arrest patients. Prospective research is required wherein LBM is measured using more reliable methods, including magnetic resonance, computed tomography, and dual-energy X-ray absorptiometry.

Author Contributions: S.E.L. and H.H.K. carried out the study design, data collection, and statistical analysis, and drafted the manuscript. M.K.C. and E.J.P. participated in the data collection. S.C. assisted with the statistical analysis and drafting the manuscript. All authors have read and agreed to the published version of the manuscript.

Funding: This research was supported by the National Research Foundation of Korea (NRF) grant funded by the Korean government (MSIT; no. 2018R1C1B60035).

Institutional Review Board Statement: This study was conducted according to the principles of the Declaration of Helsinki. It was approved by the institutional review board of Ajou University Medical Center (MED-MDB-20-283). The requirement for consent was waived due to the retrospective nature of the study.

Informed Consent Statement: Not applicable.

Data Availability Statement: Please contact author for data requests.

Acknowledgments: We thank all colleagues fighting against COVID-19 at Ajou University Hospital.

Conflicts of Interest: The authors declare no conflict of interest.

\section{References}

1. Sandroni, C.; D'Arrigo, S.; Nolan, J.P. Prognostication after cardiac arrest. Crit. Care 2018, 22, 150. [CrossRef]

2. Yao, Y.; Johnson, N.J.; Perman, S.M.; Ramjee, V.; Grossestreuer, A.V.; Gaieski, D.F. Myocardial dysfunction after out-of-hospital cardiac arrest: Predictors and prognostic implications. Intern. Emerg. Med. 2018, 13, 765-772. [CrossRef]

3. Van den Brule, J.M.D.; van der Hoeven, J.G.; Hoedemaekers, C.W.E. Cerebral Perfusion and Cerebral Autoregulation after Cardiac Arrest. Biomed. Res. Int. 2018, 2018, 4143636. [CrossRef] 
4. Roberts, B.W.; Trzeciak, S. Systemic inflammatory response after cardiac arrest: Potential target for therapy? Crit. Care Med. 2015, 43, 1336-1337. [CrossRef]

5. Lavie, C.J.; Alpert, M.A.; Arena, R.; Mehra, M.R.; Milani, R.V.; Ventura, H.O. Impact of Obesity and the Obesity Paradox on Prevalence and Prognosis in Heart Failure. JACC Heart Fail. 2013, 1, 93-102. [CrossRef] [PubMed]

6. Wang, Z.J.; Zhou, Y.J.; Galper, B.Z.; Gao, F.; Yeh, R.W.; Mauri, L. Association of body mass index with mortality and cardiovascular events for patients with coronary artery disease: A systematic review and meta-analysis. Heart 2015, 101, 1631-1638. [CrossRef] [PubMed]

7. Sandhu, R.K.; Ezekowitz, J.; Andersson, U.; Alexander, J.H.; Granger, C.B.; Halvorsen, S.; Hanna, M.; Hijazi, Z.; Jansky, P.; Lopes, R.D.; et al. The 'obesity paradox' in atrial fibrillation: Observations from the ARISTOTLE (Apixaban for Reduction in Stroke and Other Thromboembolic Events in Atrial Fibrillation) trial. Eur. Heart J. 2016, 37, 2869-2878. [CrossRef] [PubMed]

8. Geri, G.; Savary, G.; Legriel, S.; Dumas, F.; Merceron, S.; Varenne, O.; Livarek, B.; Richard, O.; Mira, J.P.; Bedos, J.P.; et al. Influence of body mass index on the prognosis of patients successfully resuscitated from out-of-hospital cardiac arrest treated by therapeutic hypothermia. Resuscitation 2016, 109, 49-55. [CrossRef] [PubMed]

9. Ma, Y.; Huang, L.; Zhang, L.; Yu, H.; Liu, B. Association between body mass index and clinical outcomes of patients after cardiac arrest and resuscitation: A meta-analysis. Am. J. Emerg. Med. 2018, 36, 1270-1279. [CrossRef] [PubMed]

10. Leary, M.; Cinousis, M.J.; Mikkelsen, M.E.; Gaieski, D.F.; Abella, B.S.; Fuchs, B.D. The association of body mass index with time to target temperature and outcomes following post-arrest targeted temperature management. Resuscitation 2014, 85, 244-247. [CrossRef] [PubMed]

11. Lavie, C.J.; McAuley, P.A.; Church, T.S.; Milani, R.V.; Blair, S.N. Obesity and cardiovascular diseases: Implications regarding fitness, fatness, and severity in the obesity paradox. J. Am. Coll. Cardiol. 2014, 63, 1345-1354. [CrossRef] [PubMed]

12. Hioki, H.; Miura, T.; Motoki, H.; Kobayashi, H.; Kobayashi, M.; Nakajima, H.; Kimura, H.; Mawatari, E.; Akanuma, H.; Sato, T.; et al. Lean body mass index prognostic value for cardiovascular events in patients with coronary artery disease. Heart Asia 2015, 7, 12-18. [CrossRef] [PubMed]

13. Wang, J.; Streja, E.; Rhee, C.M.; SooHoo, M.; Feng, M.; Brunelli, S.M.; Kovesdy, C.P.; Gillen, D.; Kalantar-Zadeh, K.; Chen, J.L. Lean Body Mass and Survival in Hemodialysis Patients and the Roles of Race and Ethnicity. J. Ren. Nutr. 2016, 26, 26-37. [CrossRef] [PubMed]

14. Huang, J.W.; Lien, Y.C.; Wu, H.Y.; Yen, C.J.; Pan, C.C.; Hung, T.W.; Su, C.T.; Chiang, C.K.; Cheng, H.T.; Hung, K.Y. Lean Body Mass Predicts Long-Term Survival in Chinese Patients on Peritoneal Dialysis. PLoS ONE 2013, 8, e54976. [CrossRef]

15. Seo, M.H.; Lee, W.Y.; Kim, S.S.; Kang, J.H.; Kang, J.H.; Kim, K.K.; Kim, B.Y.; Kim, Y.H.; Kim, W.J.; Kim, E.M.; et al. 2018 Korean Society for the Study of Obesity Guideline for the Management of Obesity in Korea. J. Obes. Metab. Syndr. 2019, 28, 40-45. [CrossRef]

16. Kulkarni, B.; Kuper, H.; Taylor, A.; Wells, J.C.; Radhakrishna, K.V.; Kinra, S.; Ben-Shlomo, Y.; Smith, G.D.; Ebrahim, S.; Byrne, N.M.; et al. Development and validation of anthropometric prediction equations for estimation of lean body mass and appendicular lean soft tissue in Indian men and women. J. Appl. Physiol. 2013, 115, 1156-1162. [CrossRef]

17. Herzog, C.A.; Ma, J.Z.; Collins, A.J. Poor Long-Term Survival after Acute Myocardial Infarction among Patients on Long-Term Dialysis. N. Engl. J. Med. 1998, 339, 799-805. [CrossRef]

18. Chae, M.K.; Lee, S.E.; Min, Y.G.; Park, E.J. Initial serum cholesterol level as a potential marker for post cardiac arrest patient outcomes. Resuscitation 2020, 146, 50-55. [CrossRef]

19. Looijaard, W.; Molinger, J.; Weijs, P.J.M. Measuring and monitoring lean body mass in critical illness. Curr. Opin. Crit. Care 2018, 24, 241-247. [CrossRef]

20. Lee, M.J.; Kim, E.H.; Bae, S.J.; Choe, J.; Jung, C.H.; Lee, W.J.; Kim, H.K. Protective role of skeletal muscle mass against progression from metabolically healthy to unhealthy phenotype. Clin. Endocrinol. 2019, 90, 102-113. [CrossRef]

21. Riesberg, L.A.; Weed, S.A.; McDonald, T.L.; Eckerson, J.M.; Drescher, K.M. Beyond muscles: The untapped potential of creatine. Int. Immunopharmacol. 2016, 37, 31-42. [CrossRef] [PubMed]

22. Perasso, L.; Spallarossa, P.; Gandolfo, C.; Ruggeri, P.; Balestrino, M. Therapeutic Use of Creatine in Brain or Heart Ischemia: Available Data and Future Perspectives. Med. Res. Rev. 2013, 33, 336-363. [CrossRef] [PubMed]

23. Pedersen, B.K.; Febbraio, M.A. Muscle as an Endocrine Organ: Focus on Muscle-Derived Interleukin-6. Physiol. Rev. 2008, 88, 1379-1406. [CrossRef] [PubMed]

24. Feng, Q.; Wang, Y.I.; Yang, Y. Neuroprotective effect of interleukin-6 in a rat model of cerebral ischemia. Exp. Ther. Med. 2015, 9, 1695-1701. [CrossRef]

25. Adamo, S.; Pigna, E.; Lugara, R.; Moresi, V.; Coletti, D.; Bouche, M. Skeletal Muscle: A Significant Novel Neurohypophyseal Hormone-Secreting Organ. Front. Physiol. 2018, 9, 1885. [CrossRef]

26. Senturk, G.E.; Erkanli, K.; Aydin, U.; Yucel, D.; Isiksacan, N.; Ercan, F.; Arbak, S. The protective effect of oxytocin on ischemia/reperfusion injury in rat urinary bladder. Peptides 2013, 40, 82-88. [CrossRef]

27. Gonzalez-Reyes, A.; Menaouar, A.; Yip, D.; Danalache, B.; Plante, E.; Noiseux, N.; Gutkowska, J.; Jankowski, M. Molecular mechanisms underlying oxytocin-induced cardiomyocyte protection from simulated ischemia-reperfusion. Mol. Cell. Endocrinol. 2015, 412, 170-181. [CrossRef] 
28. Moghadam, S.E.; Tameh, A.A.; Vahidinia, Z.; Atlasi, M.A.; Bafrani, H.H.; Naderian, H. Neuroprotective Effects of Oxytocin Hormone after an Experimental Stroke Model and the Possible Role of Calpain-1. J. Stroke Cerebrovasc. Dis. 2018, $27,724-732$. [CrossRef] [PubMed]

29. Fernando, R.; Drescher, C.; Nowotny, K.; Grune, T.; Castro, J.P. Impaired proteostasis during skeletal muscle aging. Free Radic. Biol. Med. 2019, 132, 58-66. [CrossRef] [PubMed]

30. Hume, R. Prediction of lean body mass from height and weight. J. Clin. Pathol. 1966, 19, 389-391. [CrossRef] [PubMed]

31. De Branco, F.M.S.; de Paula, A.L.B.; Rossato, L.T.; Barreiro, S.M.; Nahas, P.C.; Murta, E.F.C.; Orsatti, F.L.; de Oliveira, E.P. Comparison of predictive equations of lean mass in young and postmenopausal women. Clin. Nutr. ESPEN 2018, $24,62-65$. [CrossRef] [PubMed]

32. Moisey, L.L.; Mourtzakis, M.; Kozar, R.A.; Compher, C.; Heyland, D.K. Existing equations to estimate lean body mass are not accurate in the critically ill: Results of a multicenter observational study. Clin. Nutr. 2017, 36, 1701-1706. [CrossRef] [PubMed] 